\title{
Civilisations
}

Revue internationale d'anthropologie et de sciences

humaines

$65 \mid 2016$

Figures du malentendu

\section{Structured and unstructured misunderstandings}

Towards an anthropological theory of misunderstanding

\section{Guido Sprenger}

\section{Q OpenEdition \\ 1 Journals}

\section{Electronic version}

URL: http://journals.openedition.org/civilisations/4050

DOI: 10.4000 /civilisations.4050

ISSN: 2032-0442

\section{Publisher}

Institut de sociologie de l'Université Libre de Bruxelles

\section{Printed version}

Date of publication: 19 December 2016

Number of pages: $21-38$

ISBN: 2-9602017-0-3

ISSN: 0009-8140

\section{Electronic reference}

Guido Sprenger, "Structured and unstructured misunderstandings", Civilisations [Online], 65 | 2016,

Online since 19 December 2019, connection on 15 January 2021. URL: http://

journals.openedition.org/civilisations/4050 ; DOI: https://doi.org/10.4000/civilisations.4050

(c) Tous droits réservés 


\title{
Structured and unstructured misunderstandings
}

\author{
Towards an anthropological theory of misunderstanding
}

\author{
Guido SPRENGER
}

\begin{abstract}
Misunderstandings are not only the foundation of social and cultural anthropology but also a necessity in human communication. This articlestresses the productive and creative aspects of misunderstanding. In particular, and in complementation to hermeneutic approaches, it stresses the expansive social nature of misunderstandings. Misunderstandings involve more than two speakers, and it should be the aim of an anthropological theory of misunderstandings to follow them through the lines of communication that they produce. In particular, cultural misunderstandings can be seen as the results of contacts between social systems, as theorized by Niklas Luhmann.

One important difference is that between structured and unstructured misunderstandings. Structured misunderstandings employ terms and concepts that the partners in communication seemingly share. They communicate mostly successfully although the concepts they use are only superficially similar. This contrasts with unstructured misunderstandings in which concepts are not shared. Both types are exemplified with data from fieldwork in upland Laos. The examples serve to demonstrate that any solution of a misunderstanding is by necessity partial and full understanding would in fact terminate communication instead of reproducing it.
\end{abstract}

Keywords: Laos, Luhmann, hermeneutics, misunderstanding, religion.

Résumé: Le malentendu n'est pas seulement au fondement del'anthropologie sociale et culturelle: c'est aussi une nécessité pour la communication humaine. Cet article souligne sa dimension productive et créatrice, ainsi que sa nature sociale expansive, au-delà de-et complémentairement $\grave{a}$ - une approche herméneutique. Les malentendus engagent plus que deux interlocuteurs; toute théorie anthropologique du malentendu devrait les suivre à travers les lignes de communication qu'ils produisent. Suivant le modèle théorique de Niklas Luhmann, les malentendus culturels peuvent être interprétés comme résultant des contacts entre systèmes sociaux.

On peut distinguer malentendus "structurés » et "non structurés ». Les premiers font usage de termes et concepts que les deux parties communicantes partagent apparemment. Ces parties communiquent pour l'essentiel avec succès, même si les concepts qu'elles utilisent ne sont que superficiellement similaires. A l'inverse, lorsque les concepts utilisés ne sont pas partagés par les parties, on est face à un malentendu non structuré. Les deux cas de figure sont exemplifiés au départ de données issues de recherches de terrain dans les hautes terres du Laos. On verra dans les deux cas que toute résolution d'un malentendu ne peut être que partielle et qu'une compréhension parfaite clôturerait la communication au lieu de la prolonger.

Mots clés : Laos, Luhmann, herméneutique. 
"It is sufficient to say that one understands differently, if one understands at all."

(Gadamer, 1975: 280, transl. GS, italics in original)

The following reflections attempt to contribute to a theory of misunderstanding, a notion largely sidelined in the wide anthropological literature on communicative deficits. The point I suggest is that an anthropological contribution to the study of misunderstanding should consist in recognizing the different range of understanding and misunderstanding. Most approaches to misunderstanding consider it as an event occurring between two speakers, who might share or not share their cultural background. I suggest that misunderstandings should be considered from the perspective of longer chains of communication - either further communications between the communicators or communications with other parties. Only if such a wider range of communications is taken into account, understandings and misunderstandings can be properly analysed and categorized.

My argument proceeds in four steps. First, I formulate a critique of a specific modern ideology of communication which prevents considering misunderstanding as a normal, even necessary aspect of communication. Secondly, I offer a few remarks on philosophical hermeneutics that profoundly helps to analyse misunderstandings, but at the same time suffers from not considering fully the social dimensions of communication. Thirdly, I suggest an alternative approach to misunderstanding inspired by Luhmann's theory of social systems that helps normalizing misunderstanding as a necessary and often productive aspect of communication. Finally, I provide a contribution to an analytical taxonomy of misunderstandings by distinguishing unstructured and structured misunderstandings. Structured misunderstandings are those in which specific terms, conventional translations or other semantic devices create the semblance of understanding for the parties involved, even though the effects of the communications reveal that there is misunderstanding. Structured misunderstandings are thus often - but not always - what is conventionally called working misunderstandings. Misunderstandings without such stabilizing and structuring devices are unstructured.

\section{The ideology of understanding}

It is surprising that there is so little theorizing of misunderstanding in anthropology, even though there is a broad range of theories about communicative failure. Communication becomes difficult with people we are unfamiliar with - this is among the first experiences anyone makes with what is commonly called cultural difference. Such obvious difficulties appear as non-understanding. But while nonunderstanding is usually immediately recognized as such, misunderstanding is first taken for understanding. Only in a second step, called "realization" by HumphreysJones (1986: 147), it is recognized as miscommunication. The difference is that nonunderstanding demands only a single communication, considered as incomprehensible by the receiver, while misunderstanding is only realized by the sender after at least one more communication, a reply. This difference indicates the more complex nature of misunderstandings.

If a range of socio-cultural contexts is taken into account, certain categories of people appear to misunderstand each other more often than others and, what is more, 
quite systematically so. Maybe it was this recognition of the systemic character of miscommunication that has led, through the contingencies of European intellectual history, to the notion that different peoples have different world views, mentalities, values etc., in short, "cultures". Today, we recognize this idea as problematic, but in hindsight, we might consider it as but one historically specific attempt to address the question why misunderstandings accumulate in some social relationships while they are distributed more randomly in others. Misunderstanding, then, should be central for anthropological theorizing. ${ }^{1}$

However, theorizing about communication is not value-neutral. A strong current in the ideology of communication - maybe characteristic for modernity - gives priority to understanding as the superior value. In most European languages, misunderstanding is defined in opposition to understanding and therefore as failure vis-à-vis success, negative versus positive. This follows from a concept of language that considers it first of all as a means to transmit information as precisely as possible, a "telegraphic" device (Servais and Servais, 2009) by which information is packaged into utterances and thereby transmitted to a receiver who only needs to unpack (decode) the message. This model seems to be tenacious, even though it has been criticized repeatedly (e.g. Luhmann, 1995: 113-124) and is not universal. As Maurice Bloch, for example, has shown, Zafimanyiri consider lying as the most distinctive feature of verbal communication, not the transmission of information (Bloch, 2013: 44-46).

Anthropology, as a culturally specific practice, is subject to the same modern ideology of communication. The most common critique of theories in the discipline is the accusation that they do not properly represent social reality or the interlocutors' own understanding of it, but remain framed in the assumptions of the academic observer. Almost every turn in anthropological theory has been heralded by the claim to "take the data serious". Equally, any attempt to model understanding in anthropology was reproached - by some other criteria - as being a misunderstanding. Thus, misunderstanding is ascribed a central role, but not a welcome one. At the same time, it appears as the driving force of anthropological knowledge production. Therefore, as I will argue below, misunderstandings do not differ from communication - any communication involves the production of differences - and in some sense are just as productive of sociality as understandings (see Tsing, 1993: 31, Holbraad, 2012). Is it then possible to ascribe misunderstanding a status fitting its role as the necessary complement of understanding, at the core of some of the creative dynamics of communication?

This endeavor begins with an inevitable loop, conditioned by our ideology of communication. At once, we aim to consider misunderstandings not as the absence of something, as deficit, but as a positive phenomenon, important in itself. However, by definition, dealing with misunderstandings inevitably involves the attempt to

1 There is an important caveat to this argument. It presumes that the beings that are interacting assume that they are communicating with each other and not just reacting upon each other. Only when the former is the case, misunderstandings can be conceptualized as such, and only then, communication within one context and between contexts can be compared. If the "social contexts" I mentioned are not considered to be social by the interactors, e.g. because they involve non-social beings, this comparison would not occur. According to culturally specific notions of personhood, such non-social beings might include or exclude animals, spirits, foreigners, etc. See Servais and Servais, 2009. 
understand misunderstandings, to "realize" them in the above sense - and thereby, again, a valorization of understanding over misunderstanding, an encompassment of the latter by the former. An ideology of communication that prioritizes understanding over misunderstanding does not seem to allow a positive valorization of misunderstanding. Even while I am arguing for the value of misunderstanding, I am trying to make myself understood.

This begins with the realization of misunderstanding. Misunderstanding is usually seen as a discrepancy between the range of expected effects of a communication and its actual follow-up communications. Realizing a misunderstanding simply states the existence of such discrepancy and already involves one of the basic requirements of understanding, as taught by Husserl, the adoption of the perspective of the other (Kurt, 2004: 147). Therefore, one has to understand that one party of a communication interprets it differently than the other. This involves two more understandings: understanding the expectations (intentions) of the sender and those communications of the receiver that follow the initial communication, for example, a reaction that betrays the difference of understandings. Thus, the very attempt to relieve misunderstanding from its image of the unwelcome requires understanding - which reinforces the superiority of the latter.

However, there is a way out of this conundrum. Assigning understanding with a superior value does not necessarily imply that all misunderstanding must be eradicated - that the world is incomplete as long as misunderstanding exists. Rather, one could think of the relationship of understanding and misunderstanding in terms of a dynamic hierarchy (Dumont, 1991: chapter 9). While the idea-value of understanding occupies the higher position in most contexts, misunderstanding is its necessary complement and might even be superior in some selected contexts - for example, at the starting point of an anthropological inquiry, at a moment when questions emerge, communication is pressed forward or is deliberately made more complex and demanding. There are situations in which misunderstanding is actually highly valued, passively accepted or even actively sought, e.g. as a strategy of deception (see below). In this sense, misunderstanding is a value as well, however, one that is usually subordinated. Occupying the inferior position in a Dumontian value hierarchy, however, does not entail its elimination or demonization, but rather acknowledges its necessity.

Still, understanding remains a remote goal, the destination of an ever unfinished process (Gadamer, 1975: 282). Superior values are usually strived for but hardly ever achieved. This implicates that misunderstandings are common, while understanding is rare and possibly restricted.

\section{Hermeneutics}

In the following, I want to look at misunderstandings, first from the socially restricted perspective of hermeneutics and then from the socially expansive point of view offered by systems theory - in order to arrive at a definition of structured and unstructured misunderstandings in the context of "cultural" misunderstandings.

Since early on in its development as a branch of philosophy, hermeneutics considered misunderstandings as an inevitable, albeit undesirable, aspect of communication, as, for example, in the writings of Friedrich Schleiermacher in the early $19^{\text {th }}$ century (Schleiermacher, 1959: 92). The hermeneutics of Johann Gustav Droysen and Wilhelm 
Dilthey proposes that understanding is only possible if what is to be understood is neither entirely alien nor entirely familiar - the former would make understanding impossible, the second unnecessary (Kurt, 2004: 137). This implies that interpretation always indicates a difference between what is being interpreted and the interpretation, the act of interpreting being the transition between them. This is implied when Wilhelm v. Humboldt argues that "any understanding is at the same time a non-understanding" (Humboldt, 1965: 228, my translation). Hans Georg Gadamer, in the second half of the $20^{\text {th }}$ century, formulated this problem in more positive terms, when he posited that understanding differently means understanding at all (see opening quote, Gadamer, 1975: 280). In this respect, there is no necessary distinction between a correct interpretation and an incorrect one, an understanding and a misunderstanding. Some external third factor has to make this distinction possible (Modler, 2009: 19).

I argue that this third factor is the consideration of follow-up communications, that is, communications by which an observer can detect the effect of the misunderstanding. This observer might be one of the initial communicators or a third person. The idea is not entirely alien to hermeneutics. Central to the hermeneutic endeavor is the acknowledgment of the conditions under which the texts to be interpreted have been produced, e.g. as the result of particular personal and historical circumstances. In other words, the text is seen as a communication conditioned by other communications that add up to its "period" or "culture". Much of the early systematics of hermeneutics was concerned with an analysis of this problem (e.g. Kurt, 2004: 103-106, Schleiermacher, 1959). From there, hermeneutics has moved on to consider interpretation and understanding as a general feature of human experience (Gadamer, 1975: xxvii).

However, at least among classic hermeneutic thinkers, this tends to blur an important distinction - interpretation as a cognitive act, something that primarily happens in the mind, and interpretation as a base for further action. While Gadamer (1975: 281) criticizes the notion of understanding as a subjective experience and considers understanding rather as placing oneself within a tradition of receiving a text, he does not so much address the social dimension of understanding. This is true even as he states that the hermeneutic process should not so much be modeled upon reading a text than on involving in a dialogue (ibid., 350-351). Yet, it seems, it is a dialogue that is cut off from all the other dialogues around it. Thus, hermeneutics helps to normalize the limitations of understanding and its processual character. What is needed now is to apply these insights to the social character of understanding.

Interpretation as basis for further action, however, demands the inclusion of a wider range of communications beyond the initial dialogue. ${ }^{2}$ There is an - at least gradual difference between the interpretation of an ancient poem on the one hand or a command, an advice, a question, on the other. An ancient poet does not expect me to perform certain actions and does not check upon my correct performance, but someone giving me orders probably will compare her expectations with my performance and judge if I

2 This is true also for the important distinction between pragmatic and scholarly understanding (Kurt 2004: 38). From an anthropological perspective, scholarly discourse appears as a form of social practice, which makes the scholarly search for truth and distance from one's own interests appear as a discourse structured by specific values. Thus, it is difficult to uphold the fundamental difference posited by hermeneutics between the two types of discourse. 
have understood them correctly. In the latter case, the social process will reveal degrees of understanding and misunderstanding of a given interpretation, realized through follow-up communication. Therefore, the case of understanding or misunderstanding is often enough only decided by third or fourth parties looking at the consequences of a particular communication and judging if it had been interpreted correctly.

Thus, anthropologists should consider modeling their concepts of misunderstanding on situations that involve multiple parties. As linguist Edda Weigand (1999) and others have pointed out, a distinctive feature of misunderstanding is that the receiver is initially not aware of it. This distinguishes misunderstanding from non-understanding. First, in a social context, an initial misunderstanding will proliferate. Like many other communications, it will condition future communications, but will direct them away from the expectations of the initial sender. This consideration of successive communications is implied when I speak of the range of communication. The consequences are the stuff of many dramatic narratives of misunderstandings, which mirror the social complexity of misunderstanding.

Secondly, in order to identify a communication as misunderstanding, an observer - the original sender or someone else - needs to realize the misunderstanding and communicate this realization. A misunderstanding might be realized only after an extended chain of follow-up communications has occurred. Without realization, the misunderstanding would still pass as an understanding. Thus, both the consequences of a misunderstanding in relations beyond the initial communication and the position of the realizing observer involve a wider social arena.

One example from the literature should help to elucidate how knowledge about an expanded range of communication might help to identify understanding and misunderstanding, a case that is in many ways exemplary for the anthropological procedure. Paul Durrenberger (1975) describes a misunderstanding between Thai travelling doctors and upland Lisu villagers. The Thai provide treatment for sick villagers, but the Lisu are unwilling to pay them. This, Durrenberger explains, is due to the different ways social relationships are conceived among Lisu and Thai. The egalitarian-minded Lisu demand explicit prior agreements, while the Thai, used to relate in loose, hierarchical solidary groups, expect payment for any service rendered outside of these groups. Durrenberger's approach is classically positivist. Representatives of two different cultures misunderstand each other due to the limitations of their cultural concepts, but the anthropologist, with his knowledge acquired from a distance, sees through the situation - he understands. In this respect, he concurs with Gadamer's claim that distance to the communication enhances good interpretation (Gadamer, 1975: 281), as it highlights the necessary distinction between interpretation and its object.

However, recent theories about upland identities in Southeast Asia point out that these emerged in a clearly negotiated difference with lowland societies (e.g. Jonsson, 2014; Scott, 2009). This suggests a somewhat speculative alternative to Durrenberger's interpretation, namely as an example of intentional misunderstanding (see Mörike, this issue). While the Thai doctors certainly did not have sufficient experience with Lisu patients, the Lisu village in question had been visited by other Thai doctors before and knew hospitals. Thus, I assume that the Lisu knew exactly what to expect when they were not addressing the question of payment before treatment. The Lisu might 
have sought out the misunderstanding, turning the possibility of culturally marked miscommunication into an asset, thereby stressing Thai-Lisu difference over the universality of the market.

This possibility only becomes conceivable when the range of communications under consideration is extended. Thus, the initial transaction, the medical treatment, was based on an understanding - the Lisu patients needed treatment, the Thai provided it. This turned into a misunderstanding when follow-up communications were taken into account. However, when even more communications connected to this event were regarded, like the previous visits by Thai doctors, the interpretation changes again, suggesting one-sided understanding.

Thus, an understanding can turn into a misunderstanding if the scale and the complexity of the communications considered changes, and vice versa. Some concepts from Luhmann's theory of social systems might inspire an appropriate approach to this phenomenon.

\section{Misunderstanding as communication between systems}

The notion of cultural misunderstanding commonly assumes that communications and meaning are systemically organized, so that a communication that is sufficiently comprehensible in one of these systems becomes more difficult to understand in another. This presumes that each communication is part of a chain or network of communications that precede and follow up on it. Understanding can be defined in reference to such chains of communications. Each communication is conditioned by the expectation of certain follow-up communications that are more or less likely to happen. When we follow the successive communications, and the expectations are not met, we may speak of misunderstandings. If they keep within the range of the expected, they are understandings. Thus, an understanding is a way to connect one communication in an appropriate way to the next one. This implies the proper use of semantics, of a set of meaningful signs.

A theory appropriate to cultural misunderstandings thus should move away from the dialogue and instead highlight systemic differences. A conventional view would couch communication between systems in terms of translation. Because terms are part of specific semantics, they cannot be fully translated into a different language or semantics. This view, however, stresses the limits of translation. A less normative way of speaking about misunderstanding can be drawn from Niklas Luhmann's theory of autopoietic social systems (Luhmann, 1984). For Luhmann, social systems consist of communications - not persons or human beings - that reproduce themselves according to particular conditions (ibid., 67-68, 286-288, Luhmann, 1995: 113-117). The condition central for our present concern is the dependence on a particular semantic-a language, signs, concepts, in short, a set of differences that makes it possible to produce new communications, that is, to produce the system's own elements (autopoiesis).

The particular semantic code that reproduces communication in a system also creates the distinction between system and environment. This environment consists of everything not belonging to the system, including other social systems, psychic systems, etc.. Events in the environment are only information when they trigger communications within the system, that is, they are renderend in terms of its semantics. Information thus 
changes the system by conditioning new communications (Luhmann, 1984: 103-104, 250). Autopoietic systems thus depend on external information but process it according to their own conditions. This is, they are operatively closed and open at the same time (ibid., 25, 63-64, 557-558).

The reproduction of communication therefore creates and maintains the systemenvironment difference. This means that the very process that establishes any autopoietic social system in the first place also implies that it differentiates from other systems. The specificity of the system's semantic thus creates the conditions of its maintenance and of misunderstandings. Thus, no social system without system-environment difference and therefore, no social system without misunderstandings.

Most social systems with a degree of stability over time are complex, that is, not every element (communication) can be connected to every other element. Thus, in order to operate, a complex system needs semantic and institutional means of selecting elements to connect to other elements. Thereby it reduces its own complexity and that of its environment (ibid., 50, 252, 291, 404). The way a system selects communication and reduces complexity provides it with a specific sensitivity to events in the environment. That is, it produces more communications in reaction to some events in the environment (e.g. from certain other systems), and less so to others (Luhmann, 1995: 16). No system can reproduce the complexity of another system in its entirety, as their rules of selection and their semantics differ. Again, the operation of social systems differentiation produces misunderstandings.

What is the nature of misunderstandings under these conditions? Each communication is part of a connective chain within a system. Therefore, if a communication triggers follow-up communications in a different system, the latter cannot reproduce the entire chain that produced the initial communication. The other system will necessarily process it differently than the original system, that is, it will produce new communications by different means of selection and different semantics. Misunderstanding between systems thus means: differentiated connectivity. The difference between what a communication accomplishes within its system of origin and within a different system only becomes apparent when we look at further communications, that is, when we expand the range of communications taken into account. It is only then that misunderstandings become apparent.

I suggest thus that each communication triggering communication in two or more social systems - especially systems with different semantics - is at least partially misunderstood. Difference in semantics could be termed "culture", although in case of societies with a great degree of subsystem differentiation (like the differentiation into law, politics, art, etc. in modern societies), this term, which often implies world view or thought, would be misleading.

Therefore, every time one system produces communication as a reaction to communication in a different system, misunderstandings arise - if only a wider range of follow-up communications is considered. The lines of communication diverge in the two systems. Much of what passes as understanding simply consists of the refusal to follow these implications. Without an observer recognizing the divergent communication lines, nobody will declare the understanding to be a misunderstanding. Even if an observer realizes the misunderstanding, it only becomes relevant if the observer communicates her insight back into the systems. 
Each of these steps - seeming understanding on a narrow scale, divergence on a wider scale, recognition as misunderstanding, feedback etc. - is contingent. As each step in this process is less likely to happen than its predecessor and is again a selection of various possibilities, it becomes increasingly unlikely that a misunderstanding is identified and "corrected". This suggests that for each corrected misunderstanding there are many that remain unidentified. Once again, misunderstandings appear as rather normal.

If misunderstandings are realized, they can be valorized positively or negatively. But this valorization is in itself cultural and not analytical. As Luhmann has remarked, if sociology is not understood as a means to engineer society and to avoid anti-social events, any misunderstanding is productive. The misunderstood communication leads to follow-up communications that are less predictable than what has been produced before. Therefore, even a misunderstood communication is creative, as it changes the conditions for the production of further communication within the receiving system (Luhmann, 1984: 163).

The next question is then, how to analyze misunderstandings that occur between two systems. While in relationship with each other, systems might develop conventionalized ways of translating communication, as semantic relay points. However, these conventions do not prevent misunderstandings but might merely structure them. I therefore distinguish between structured and unstructured misunderstandings.

\section{Structured and unstructured misunderstanding}

As a first step, I thus propose a typology of misunderstandings - a typology, of course, that does not pigeonhole the phenomena but highlights the way they are organized. Earlier attempts of typologies of misunderstandings in anthropology seem rare, although they are more prolific in linguistics (Humphreys-Jones, 1986, Weigand, 1999) and also have a tradition in hermeneutics (e.g. Schleiermacher, 1959). However, in these typologies, cultural misunderstandings constitute but one large category, and one whose relevance might be debated (Kaur, 2011). In anthropology, Fabian (2001) differentiates misunderstandings by their linguistic features (phonetics, semantics, speech events). Henry (2003) distinguishes between outsider misunderstandings - by external anthropologists and other foreigners - and insider misunderstandings - by locals in respect to their own (textual) traditions. This example raises not only the question if insiders can get their own culture wrong, but also, how to deal with diverging interpretations, highlighting once again that misunderstanding is a kind of understanding. Both approaches suggest that differences between misunderstandings can be made by considering chains of communications and the social relationships along which they are produced. Fabian (2001) describes such chains and networks of communication as contexts. As he points out, an observer can identify a misunderstanding only by reference to a context. However, I would question the distinction between communication as foreground and context as background. The context is an accumulation of communications itself, and in respect to misunderstandings, it coagulates as context when a misunderstanding is identified.

As part of such a typology, I suggest to distinguish structured and unstructured misunderstandings. Unstructured misunderstanding implies the imposition of one 
system's concepts upon the semantics and code of another system. Structured misunderstanding means that the two systems conventionally agree upon a set of terms or translations, even though the terms relate to very different other terms and communications in the two systems respectively. There is thus a shared assumption of understanding within a certain range of communications, while there is discrepancy beyond it. This means, if we consider any communication as embedded in chains of communications, some shorter and some longer, a structured misunderstanding is often a misunderstanding that works as an understanding in medium to long chains. ${ }^{3}$ Only when an even wider range of chains of communication is considered, the divergence of the understandings belonging to the two systems becomes apparent. Unstructured misunderstandings work as understandings only when one system considers a very limited range of communications of the other system. They do not make follow-up communications predictable and are, if stable, only stable within one of the systems. In these cases, one party applies its own concepts to the representations of another one without knowledge by the other party. The conceptual framework of understanding is thus one-sided: Each side has concepts to "understand" the other, but these sets of concepts are separate and exclusively used in their respective systems. This is, they are quite asymmetric, while structured misunderstandings produce more symmetric chains of communication in the respective systems.

With structured misunderstandings, which have become conventional relay points between different systems, the likelihood of realization decreases even more. Related communications may deliberately not be taken into account. Consideration of followup communications is curtailed at some point, observers cast a blind eye, as long as no serious consequence arises.

Of course, the distinction between unstructured and structured misunderstandings is not an airtight one, but helps to analyse any misunderstanding more precisely. In the next two sections, I will provide examples of both types of misunderstandings.

\section{Unstructured misunderstanding}

I will draw the first example from my own field experience among Rmeet, nonBuddhist swidden cultivators in upland Laos. According to the Rmeet, I was there to study their language, which was more plausible for them than studying culture. I stopped correcting them on this issue after a while, thus producing a typical example of intentional misunderstanding between anthropologist and interlocutors (see Mörike, this volume).

At the time of my initial research in 2000, when the following events occurred, I was structuring my own understanding of ethnographic data along a system focusing on ritual and socio-cosmic cycles. Thus, what occurred in ritual would be more

3 When Kalberg (1987) speaks of "structured" or "patterned" misunderstandings, he is merely pointing out that misunderstandings become more predictable when they are produced by cultural difference. Among his examples of misunderstandings between Germans and Americans, only the misunderstanding surrounding the terms "friendship" and "Freundschaft" would count as structured in my sense. The two terms seem clearly translatable into each other but in fact denote two different types of relationships, with often disappointing results for the people concerned. This is an example of a misunderstanding that is structured but not a "working misunderstanding." 
important than non-ritual factors, and finding a cycle would corroborate my model. It would also pass as information connective to the anthropological community, a different social system I wanted to communicate within via my findings. Even though many anthropologists stress the importance of variability, process and multivocality, the textual models they produce are expected to be coherent and closed, as anyone whose work went through a review process can testify. The production of coherent models - at least on the level of the published text - is thus part of the semantic rules of academic knowledge production. If the closure of models would be present in the data, it seemed to me, all the better. The transition from the Rmeet social system to the anthropological community would then be rather smooth. Numerous anthropologists hold that such rapprochement of local and academic models is a hallmark of good anthropology.

For Rmeet, the preconditions of successful rice cultivation are good relations with certain spirits, in particular those of the land and the spirit of rice (see Izikowitz, 2001; Sprenger 2006a, 2006b). In particular the rice spirit, which embodies the abundance of rice, needs to be summoned from the field into the field hut and later into the granary. This is accomplished by rituals involving objects called chenüm ngo that attract the spirit. While some chenüm ngo are common herbs, the most powerful ones are cherished heirlooms usually kept in the granary. These are best described as curio, strange and displaced objects, ranging from seashells to Buddha amulets, rounded pebbles found in the mountains or ceramic ware found in the ground.

But one category of objects stands out. These are stone adzes from a time prior to the use of metal implements, that are sometimes found in the ground. Significantly, these adzes are considered as the tools of lightning strikes that are spirit-like beings which use them for felling trees. ${ }^{4}$ The adzes are particularly powerful chenüm ngo and are considered as gifts from the rice spirit. Lightning spirits, however, demand a series of prescriptions to be observed by those whose house or field they have struck. Only at the beginning of the next annual field cycle, the lightning spirits return to their villages in the sky, and the prescriptions are lifted.

While ngo means rice, the meaning of chenüm remained obscure to me for a while. In Takheung village, where I conducted my research in 2000 to 2002, it is phonetically identical with the word for thunder. Thunder is closely associated with the annual rice cycle. The first thunderbolts and rainfalls after the dry season announce the beginning of a new cycle which is recognized in each household with a small ritual. The fields are tilled during the entire rainy season, but the rains cease before the harvest. Only then, the female household head takes chenüm ngo from the granaries and reveals them to the rice spirit.

Thus, the thunder is a phenomenon of the sky for the time of the rainy season and makes the rice grow. Occasionally, lightning strikes and leaves physical manifestations of thunder on the earth, in the form of stone adzes. These items also support the abundance of the rice, transforming the fertilizing power of the rain into the success of the harvest. The thunder of the sky transforms into the "thunder" of the rice, the chenüm ngo, which only emerge from the family granaries after the thunder of the sky has disappeared. Only after the harvest and the dry season, when the objects are back into

4 For further examples of this notion in Southeast Asia, see Janowski and Barton (2012). 
the granaries, the thunder returns to the sky. Chenüm thus moves in a transformative cycle between sky and earth, as a fertilizing power.

This last paragraph was my interpretation about half a year into my fieldwork. It was a beautiful model, but it was wrong. About a month later, I became aware that chenüm as thunder and chenüm as rice spirit bait were just homophones. This became clear when I visited a neighboring village in which the first word was identical, but the latter was pronounced senüm, which was also well understood in my village of residence. Senüm was better translated as "medicine", or effective substance more generally. I had not noticed this, because in everyday speech, the Rmeet word for medicine had been almost entirely replaced by the Lao loanword yaa. It was mostly in ritual contexts, as with the "rice medicine", that the old word was still in use. The Rmeet of Takheung confirmed that chenüm/senüm was a separate word, meaning the Lao word yaa, and that the chenüm of the sky, thunder, could not be translated this way.

Of course, my interlocutors had told me before that chenüm of the sky and chenüm ngo were different, when I started to explain my model, but I had not understood what kind of difference they meant - if there was a mere homophone or if there was a continuity of meaning, e.g. like in the Rmeet word klpu that covers different entities like personal souls, the spirits of the dead and occasionally the spirit of rice. These would also be said to be different, but semantically it is the same word. I tended to keep thinking that, in this case, the semantic meaning was continuous as well, as this would make it easier to reproduce my data in the semantic system of anthropology. The semantic continuity of the two chenüm thus was information for a system that aimed at building coherent anthropological models, while their discontinuity was information for the Rmeet system. I thus did not only misunderstand the difference between chenüm and chenüm ngo, but also the notion of non-identity that the Rmeet tried to communicate to me.

The misunderstanding was thus unstructured and asymmetric. It was not based on agreement and fell apart quickly, as soon as the chains of communication grew - by doing more interviews and visiting a different village.

\section{Structured misunderstanding}

Structured misunderstandings, conventional translations or shared terms, often function as stable relay points between social systems. They enhance the systems' sensitivity to each other and control selections of follow-up communications between them, thus reducing the complexity of their relationship.

Structured misunderstandings are most prominent now in situations of globalization. Globalization, in many respects, is the proliferation of modern concepts in local discourses. Such concepts are therefore transcultural communication devices. It is not that such devices were absent before the advent of globalization, but they have become better documented and have raised more attention than in previous paradigms. There are numerous good examples of such processes in the literature. Losonczy and Mesturini Cappo (2014), for example, show how the ritual of ayahuasca serves as a structured misunderstanding that is working between Amazonian shamans and Euro-American neo-shamans. Gershon (2006), however, demonstrates how the concept "culture", as 
employed by Samoan migrants, although being shared with their US counterparts, sometimes fails as a working misunderstanding.

Julie Livingston (2007) provides another example. In $20^{\text {th }}$ century Bechuanaland, at least two different medical systems were operative. Both can be considered as systems in Luhmann's sense. They were structured by a specific terminology of illness and healing and reproduced themselves by acting upon contingent information from their environment - cases of illness - that were described in the system's semantics. These systems were, of course, not groups of people but rather kinds of communication. Still, they had relay points that served the translation of concepts that were actually quite different.

Besides modern biomedicine, there was a local medical system called Bongaka, which its practitioners described as traditional and unchanging. This description, I suggest, was employed to differentiate it from biomedicine in a way that cast it as modernity's other. Thus, there was an idiom of differentiation into "unchanging tradition" and "changing modernity" at work. However, like any other social system, Bongaka was dependent on external information, and this served to transform the system - in particular in its relation to biomedicine. The notion of tradition seemingly "closes" the system but in fact conditions its peculiar way of processing information.

The way this works becomes apparent in the case of tuberculosis, a common disease in Bechuanaland. Due to its professed traditionality, Bongaka did not adopt the new concept of tuberculosis but identified it with the traditional illness of thibamo. Thibamo was indicated, among others, by coughing blood, like tuberculosis, but it was also seen to be caused by the infidelity of the patient's wife. Its prevalence thus indicated a social crisis - an increase in marital infidelity due to the absence of husbands during World War II or labour in mines. The isolation of tuberculosis patients in biomedicine was translated in Bongaka into a prohibition of sexual contacts. Still, practitioners of both medical systems could communicate by translating thibamo into tuberculosis and vice versa. This came at the price of the reduction of complexity. For the biomedical system, the relationship between ill bodies and dysfunctional marriages was no information it could process. Equally, the presence of germs was no information for Bongaka. However, the shared identification of the two concepts with certain patients enabled communication and even stabilized it. Still, their diagnoses led to entirely separate follow-up communications, leading to different types of treatment. In this sense, there was misunderstanding, as a practitioner of Bongaka would be unable, with his conceptual equipment, to grasp the way biomedical personnel acted upon the diagnosis, and vice versa.

An example drawn from my fieldwork in Southern Laos concerns the notion of "religion". It is well known that world religions spread for entirely different reasons than missionaries intend (e.g. Macdonald, 1992), but in this case, the general term "religion" is at stake. The term, with its background in Christianity and, later, enlightenment, is translated in Southeast Asia variously with terms with a different, but similarly biased history. In Laos, as in Thailand, satsana had been chosen, a word used by Buddhists in order to specify the - ultimately transient - practices and institutions founded by the Gotama Buddha and to be renewed and overcome by the Maitreya Buddha some millennia in the future. This term has been transformed into an equivalent of "religion" in a global discourse - thus, today there is satsana islam, satsana kerit (Christianity) 
etc. Thus, what has been the signifier of a transient version of a universal truth has become the signifier of the relativity of cosmologies.

As far as translation is concerned, satsana and religion seem to be translatable easily enough. However, if we widen the range of communications, it turns out that the connectivity of the term becomes more dubious. The point of divergence is marked by the category satsana phi, that is conventionally translated as "religion of spirits". Like in any other modern nation state, religious affiliation in Laos appears in percentage of population in the census, thus assigning each person to one religion only or to none. This already implies a notion of religion that is based on a Western, mostly Abrahamitic notion of religious exclusivity and has spread worldwide through the institution of the nation-state. However, in Laos, spirit religion (rendered as "animism") is explicitly "not regarded as a religion" (Steering Committee 2006: 6). This was also mirrored by government officials. A local academic laughed when he told me that some people tried to write "spirit religion" in forms asking for their affiliation - the category officially does not exist.

This attempt to inforce a European-modern conception of religion, however, is upended by parts of the population. In my current fieldwork in southern Laos, the conflict between notions of satsana becomes quite apparent. In some of the villages north of the district capital Paksong, ethnic Jru' (Loven) villagers claim that they practice two religions, satsana pud (Buddhism) and satsana phi (spirit religion). In the Lao context, this is unusual. Buddhists in Laos do ritualize their relationships with spirits but in general do not consider this as satsana. They prefer the term theu, "to venerate", in this context. Still, the term satsana phi is colloquially common for the practices and beliefs of non-Buddhists, often used by the latter themselves. Thus, while the spirit-related rituals of Buddhists and non-Buddhists are indeed identified with each other by people in Laos, they are normally only called satsana in respect to non-Buddhists.

However, Jru' villagers identify with both "religions", thus messing up the attempt to define religion as exclusive and identifiable on the basis of persons. Thereby, they at once equalize the two systems by valorizing both as "religion", and stress a hierarchy between them. In cases of conflict - for example, when the timing of mortuary rituals needs to be decided upon - Buddhism is the structuring element, and the experts of satsana phi have to fit their own rituals into the Buddhist sequence.

Another type of ritual expert in satsana phi are diviners called yaamuan. However, in the village with two satsana, I encountered great difficulties in identifying and interviewing the yaamuan, as she kept stressing what a good Buddhist she was. It seemed that at least in relationship to me, the outside ethnographer, the state-oriented and official religion was pushed to the fore. Thus, the enlightened notion of a nonhierarchical coexistence of different religions was also not part of Jru' villagers' concept of satsana. Rather, people could have two satsana at once, but in a hierarchical order.

This is also the case in a different Jru' village which most people I talked to identified as "doing old traditions" and being satsana phi. But when I asked one of the headmen how villagers had registered during the 2015 nationwide census, he replied that $80 \%$ identified as Buddhists. One of the ritual experts then explained to me that, "we do much satsana phi here and only a little Buddhism". However, when I asked him how he had registered in the census, he replied, as a Buddhist: "It's the census, it's for the government". Once again, the two religions were not mutually exclusive, 
but hierarchized. The census appears as a hegemonic way of reducing complexity, but reveals its limitations when further communication is taken into account.

Thus, the notion of satsana in the modern sense of religion, not just as a word for Buddhist practices, was introduced in the context of modern state building. In this communicative system, it denotes exclusive membership, belief and often a conceptually egalitarian relationship between religions as well as a distinction between immanence and transcendence (Luhmann, 1997). But this concept of a state born from such modernist concepts like nationalism and socialism was taken up by the population in rather different senses. In the ethnic Jru' system, satsana does not differentiate people but rituals and institutions, and it does not imply a symmetric relationship. First, the notion of a satsana of spirits was added, and second, the notion left room for the coexistence of several satsana, as in fact is common in Buddhist societies (e.g. Holt, 2009; Kirsch, 1977). In particular as Buddhism is not a religion one converts to at once and exclusively, but rather consists in the - often gradual - adoption of Buddhist practices, the self-description of Jru' villagers is plausible. Satsana here works as a relay point between state concepts and local practices, but one that contradicts the use of the term by the state when its connective communications and meanings are taken into account. In this case, no observer I am aware of, except maybe the anthropologist, took notice of the misunderstanding, and therefore, the realization was not fed back into the systems. In fact, on the level of the two systems, the misunderstanding remained to be an understanding, enabling communication across the system divide.

\section{Conclusions}

In order to develop an anthropological theory of misunderstandings, two strategies seem helpful. First, misunderstandings should be considered not only as inevitable but as productive. In Gadamer's hermeneutics, misunderstanding and prejudice should be worked against, but at the same time, they indicate the necessary condition of a separation between interpretation and its object. The first of my case studies indicates how specific misunderstandings can be overcome, while the second tells of how certain terms like satsana reproduce not only the difference between a term and its interpretation, but at the same time situate this difference on the boundary between two systems and their respective environments. From a Luhmannian point of view, the reproduction of the systems hinges upon the maintenance of the system-environment difference, the corresponding reduction of complexity of the environment and thus the production of misunderstandings.

Second, anthropology needs to overcome hermeneutic and linguistic models of communication that are derived from a dialogue between two individuals. Two factors need to be taken into account instead. The first is the follow-up communications with third and fourth parties that reveal if and at which point a misunderstanding happens. This occurs when the expectations implied by the initial communication are altered in the course of further communications, e.g. when a command or assignment changes when communicated to third parties. The second aspect concerns the question, if and how the divergence of communication chains is recognized and if attempts to align them are being made. This demands an observer of follow-up communications - not necessarily someone different from the original sender and receiver, but certainly 
looking at the follow-up communications from a different, more distant point of view. Only observation turns an understanding into a misunderstanding - a point presumably agreeable for hermeneutics.

One important factor in determining the extent of communications that a misunderstanding affects and the specification of the observer who identifies it, is the distinction between structured and unstructured misunderstanding. Both notions refer to differences in information processing between social systems and the question if there are relay points between them and how these function. Different systems process information differently and therefore select different follow-up communications in reaction to an initial communication. Following the divergence of these communication chains means to identify misunderstandings.

In unstructured misunderstandings this divergence can easily be detected when longer chains of communication are taken into account. Structured misunderstandings consist of a convention of communication between two systems, in contrast to unstructured misunderstandings, where such relay points are lacking. Therefore, structured misunderstandings can be sustained as understandings for a much longer period of time, and a much finer-grained analysis is necessary to detect the divergence in different systems.

However, the term "misunderstanding" comes with a normative load. What we need is a conceptual leap of the kind that distinguishes "interculturality" and "transculturality", according to Welsch (1992). While interculturality assumes the mutual opacity of cultures and their contact as problematic, transculturality focuses on the multiple legibility of cultural representations. Multiple legibility is not very different from differentiated connectivity. It means that a single communication or representation is the result of a lineage of communications, but, when appearing as information for another system, becomes part of quite a different chain. To describe this situation as "misunderstanding" thus involves, first, a recognition of the difference, and second, a valorization.

In many respects, valorization is inevitable. But even if misunderstanding is assigned an inferior position relative to understanding, this does not necessitate its negation. Still, misunderstanding has value as a productive and creative way of communicating. The lines of communication in the receiving system change in the attempt of interpreting external information, and do so, in often unpredictable ways, when misinterpreting. Thus, what appears as cultural misunderstanding from one point of view is transcultural production of communication from another.

\section{Acknowledgements}

I would like to express my gratitude to Frauke Mörike, Thomas G. Kirsch and the two anonymous reviewers for their very helpful discussions and comments. 


\section{References}

Bloch, Maurice, 2013. In and out of each other's bodies: Theory of mind, evolution, truth, and the nature of the social. Boulder/London: Paradigm.

Dumont, Louis, 1991 [1983]. Individualismus: zur Ideologie der Moderne. Frankfurt/New York: Campus (first: Essais sur l'individualisme. Paris: Seuil).

Durrenberger, Paul E., 1975. "Understanding a misunderstanding: Thai-Lisu relations in Northern Thailand." Anthropological Quarterly, 48, pp. 106-120.

FABIAN, Johannes, 2001. "Ethnographic misunderstanding and the perils of context", in J. Fabian, Anthropology with an Attitude, pp. 33-52. Stanford, CA: Stanford University Press.

GADAMER, Hans-Georg, 1975. Wahrheit und Methode. Tübingen: Mohr (4 ${ }^{\text {th }}$ printing).

Gershon, Ilana 2006 "When culture is not a system: Why Samoan cultural brokers cannot do their job." Ethnos, 71 (4), pp. 533-558.

Henry, Edward O., 2003. "The Jayamala rite in Eastern North India: Outsiders' and insiders' misunderstandings.” Journal of Anthropological Research, 59 (4), pp. 511-530.

HolbraAD, Martin. 2012. Truth in motion: The recursive anthropology of Cuban divination. Chicago: The University of Chicago Press.

Holt, John, 2009. Spirits of the place: Buddhism and Lao religious Culture. Honolulu: University of Hawai' $\mathrm{i}$ Press.

Humboldt, Wilhelm von, 1965 (1830-1835). “Ueber die Verschiedenheit des menschlichen Sprachbaues und ihren Einfluss auf die geistige Entwicklung des Menschengeschlechts”, in W. v. Humboldt, Schriften zur Sprachphilosophie. Werke in fünf Bänden ; III, pp. 368-756. Darmstadt: Wissenschaftliche Buchgesellschaft.

Humphreys-Jones, Claire, 1986. An investigation in the types and structure of misunderstandings. PhD thesis, University of Newcastle upon Tyne.

IzIKowitz, Karl Gustav, 1979 [1951]. Lamet: hill peasants in French Indochina. New York: AMS Press.

JANOWSKI, Monica and Huw BARTON, 2012."Reading human activity in the landscape: stone and thunderstones in the Kelabit Highlands.” Indonesia and the Malay World, DOI:10.1080/13639811.2012.709005.

Jonsson, Hjorleifur, 2014. Slow anthropology: Negotiating difference with the Iu Mien. Ithaca, NY: Cornell University Press.

KalberG, Stephen, 1987. "West German American interaction forms: one level of structured misunderstandings." Theory, Culture and Society, 4, pp. 603-618.

KaUR, Jagdish, 2011. "Intercultural communication in English as a lingua franca: Some sources of misunderstanding." Intercultural pragmatics, 8 (1), pp. 93-116.

Kirsch, A. Thomas, 1977. "Complexity in the Thai religious system: in interpretation." Journal of Asian Studies, 36 (2), pp. 241-266.

KURT, Ronald, 2004. Hermeneutik: eine sozialwissenschaftliche Einführung. Konstanz: UVK.

Livingston, Julie, 2007. "Productive misunderstandings and the dynamism of plural medicine in MidCentury Bechuanaland.” Journal of southern African Studies, 33 (4), pp. 801-810.

Losonczy, Anne-Marie and Silvia Mesturini CAPPO, 2014. "Ritualized misunderstanding between uncertainty, agreement, and rupture: communication patterns in Euro-American Ayahuasca ritual interactions", in Beatriz Caiuby Labate and Clancy Cavner (eds), Ayahuasca religion in the Amazon and beyond, pp. 106-128. London: Oxford University Press. (Retrieved from Oxford Scholarship Online)

Luhmann, Niklas, 1984. Soziale Systeme: Grundriß einer allgemeinen Theorie. Frankfurt am Main: Suhrkamp. 
-, 1995. Soziologische Aufklärung 6: Die Soziologie und der Mensch. Opladen: Westdeutscher Verlag.

-, 1997. Die Religion der Gesellschaft. Frankfurt am Main: Suhrkamp.

Macdonald, Charles, 1992. "Protestant missionaries and Palawan natives: Dialogue, conflict or misunderstanding?” JASO - Journal of the Anthropological Society of Oxford, 23 (2), pp. 127-137.

ModLer, Klaus Werner, 2006. Das Segel des Theseus: Aufsätze über das Missverstehen. Wien: Passagen.

Schleiermacher, Friedrich, 1959. Hermeneutik. Heidelberg: Winter. (Abhandlungen der Heidelberger Akademie der Wissenschaften, Philosophisch-Historische Klasse ; 1959 (2)).

Scotт, James C., 2009. The Art of not being governed: An anarchist history of upland Southeast Asia. New Haven/London: Yale University Press.

Servais, Christine and Veronique Servais, 2009. "Le malentendu comme structure de la communication." Questions de communication, 15, pp. 21-49.

Sprenger, Guido, 2006a. Die Männer, die den Geldbaum fällten: Konzepte von Austausch und Gesellschaft bei den Rmeet von Takheung, Laos. Berlin: LitVerlag.

-, 2006b. "Out of the ashes: Swidden cultivation in Highland Laos.” Anthropology today, 22 (4), pp. 9-13.

Steering Committee for Census of Population and Housing, 2006. Results from the population and housing census 2005. Vientiane: (Government of Lao P.D.R.).

Tsing, Anna Lowenhaupt, 1993. In the realm of the diamond queen: marginality in an out-of-the-way place. Princeton, N.J: Princeton University Press.

WeIgand, Edda, 1999. “Misunderstanding: the standard case.” Journal of Pragmatics 31, pp. 763-785.

WeLsch, Wolfgang, 1992. "Transkulturalität: Lebensformen nach der Auflösung der Kulturen.” Information Philosophie, 1992 (2), pp. 5-20. 